\title{
CUESTIONES DEL PROCESO MONITORIO EN HONDURAS ASPECTOS COMPARATIVOS CON EL MODELO ESPAÑOL
}

\section{Luis E. Maljik Flores ${ }^{1}$}

DOI: https://doi.org/10.5377/lrd.v41i1.10489

\section{RESUMEN:}

El objeto de este trabajo de investigación es efectuar un análisis de algunos aspectos puntuales del proceso monitorio, el cual nos resulta de interés por ser una de las novedades introducidas por el Código Procesal Civil (CPC). De igual manera se busca brindar una visión comparativa del monitorio español a efecto de conocer algunas reformas que se han producido en el mismo para procurar una mayor efectividad en su aplicación, todo esto considerando que la Ley de Enjuiciamiento Civil española sirvió de inspiración para la creación del CPC. Este instrumento procesal posee como finalidad tutelar el derecho de crédito de forma rápida y efectiva.

\section{PALABRAS CLAVE:}

Acreedor, Crédito, Cuantía, Deudor, Oposición, Pago, Titulo Ejecutivo

Fecha de recepción: 06 de mayo de 2020 Fecha de aprobación: 30 de octubre de 2020

1 Abogado. Máster en Derecho Procesal Civil por la Universidad Tecnológica de Honduras. Titulo de Posgrado en Derecho Constitucional y Derechos Humanos por la Universidad de Buenos Aires, Argentina. Maestrante de Propiedad Intelectual y Derecho de las Nuevas Tecnologías por la Universidad Internacional de la Rioja, España. Correo: luismaljik@hotmail.com 


\title{
ISSUES OF THE MONITORING PROCESS IN HONDURAS COMPARATIVE ASPECTS WITH THE SPANISH MODEL
}

\author{
Luis E. Maljik Flores ${ }^{2}$
}

DOI: https://doi.org/10.5377//rd.v41i1.10489

\begin{abstract}
:
The purpose of this research work is to carry out an analysis of some specific aspects of the monitoring process, which we find of interest as one of the novelties introduced by the Code of Civil Procedure (CPC). Likewise, it seeks to provide a comparative view of the Spanish monitor in order to know some reforms that have been produced in it to seek greater effectiveness in its application, all considering that the Spanish Civil Procedure Law served as inspiration for the creation of the CPC. The purpose of this procedural instrument is to protect the right of credit quickly and effectively.
\end{abstract}

\section{KEYWORDS:}

Creditor, Credit, Amount, Debtor, Opposition, Payment, Executive Title

Date received: May 06, 2020 Approval date: October 30, 2020

\footnotetext{
2 Lawyer. Master in Civil Procedural Law from the Technological University of Honduras. Postgraduate Degree in Constitutional Law and Human Rights from the University of Buenos Aires, Argentina. Master of Intellectual Property and New Technologies Law from the International University of La Rioja, Spain. Email: luismaljik@hotmail.com
} 


\section{INTRODUCCION}

El Código Procesal Civil Hondureño de 2006 (CPC), decreto núm. 211- 2006, que entró en vigor de forma definitiva a partir de Noviembre de 2010, surge por la necesidad de otorgar una verdadera tutela judicial efectiva a las controversias que se sometan a la jurisdicción civil, tal como lo estableció la Comisión Legislativa dictaminadora del Proyecto de CPC, sustentando el anhelo de todos los hondureños de lograr una tutela judicial pronta y accesible, así como el derecho a un fallo justo por parte de los tribunales de justicia; exigencias que ya no satisfacía el antiguo Código de Procedimientos Civiles de 1906, concebido para una realidad social distinta a la actual.

Para favorecer la lectura y comprensión del presente trabajo, se ha estructurado de manera sistemática. De esta manera, la investigación se inicia con una aproximación a algunos aspectos básicos para comprender la finalidad del proceso monitorio tales como su naturaleza, y ámbito de aplicación.

Seguidamente, se analiza lo relativo a la competencia judicial para el conocimiento de este proceso, en el cual se podrá apreciar que esta puede radicar tanto en los Juzgados de Paz como en los Jugados de Letras en razón de la cuantía de la reclamación.

La investigación prosigue estableciendo los aspectos que deben tenerse en cuenta por parte del Juez para la admisión de esta clase de proceso, y las consecuencias de su admisión. Seguidamente, se desarrolla las distintas actitudes que puede asumir el deudor una vez efectuado el requerimiento respectivo. En este apartado analizamos los distintos efectos que pueden producirse a partir de la actitud asumida por el demandado.

Finalmente, se realiza una breve aproximación a la posibilidad que existe en España de llevar al ámbito del proceso monitorio, reclamaciones con ocasión de gastos comunes producidos en comunidades de propietarios de inmuebles urbanos, posibilidad que no se encuentra regulada expresamente en el proceso monitorio hondureño, y lo cual puede resultar de interés para futuras reformas legislativas.

Finalmente se formulan las distintas conclusiones a las cuales se llegó a lo largo de esta investigación, y las propuestas de mejora a efecto de obtener un mayor provecho de este proceso. Se cierra el trabajo con la relación bibliográfica (doctrina, legislación y jurisprudencia) cuya lectura y análisis sirvió de base para el desarrollo de esta investigación.

\section{METODOLOGÍA}

El presente trabajo constituye un extracto de la investigación realizada como trabajo final de un curso tomado en la Escuela Judicial de España con sede en la ciudad de Barcelona. El orden sistemático del trabajo se construyó a partir de la regulación existente en el derecho positivo sobre la materia tanto en Honduras como España. Este análisis fue complementado con el material doctrinal y jurisprudencial obtenido en donde se aplicó el método analítico, sintético, y deductivo, este último a efecto de formular las conclusiones globales de la investigación. 
Un gran aporte para el análisis y a su vez la construcción de los subtemas, fue el estudio de la jurisprudencia de los tribunales españoles y del Tribunal de Justicia de la Unión Europea a la cual se accedió.

\section{NATURALEZA DEL PROCESO MONITORIO Y AMBITO DE APLICACIÓN.}

El proceso monitorio surge en la edad media italiana en el siglo $\mathrm{XIII}^{3}$, con el fin de crear de forma expedita un título ejecutivo, ante las exigencias sociales y/oeconómicas de laépoca, cansadas de tener que someterse a un proceso tan extenso y solemne como el ordinario. Este proceso puede concebirse como una solución a la mora y/o problema de funcionamiento de la administración de justicia, ante el atasco de los tribunales del orden civil, como modo de evitar los numerosos procesos declarativos de reclamaciones de pago. Desde su naturaleza jurídica, es evidente que no podemos calificar al proceso monitorio como un proceso civil declarativo, al contrario, uno de sus caracteres esenciales es precisamente la ausencia de toda fase declarativa debido a los siguientes aspectos:

a) $\mathrm{Si}$ el requerimiento de pago es atendido por el deudor (finaliza el proceso monitorio $\mathrm{y}$ procede el archivo de actuaciones).

b) Cuando el deudor no paga ni se opone al derecho de crédito reclamado (finaliza el proceso monitorio y se dicta auto mandando a iniciar la ejecución).

\footnotetext{
3 Motiño, K. (2013) El Proceso Monitorio en el nuevo Código Procesal Civil Hondureño (Tesis Doctoral), Universidad Jaume I, www.uji.es.
}

c) Cuandoeldeudor seopone expresamente en tiempo y forma (finaliza el proceso monitorio y se transforma el mismo en proceso ordinario o abreviado según la cuantía de la reclamación).

GIMENO SENDRA refiere que "el denominado proceso monitorio no es, en puridad, un proceso, sino un procedimiento para obtener un requerimiento judicial para el pago rápido de una deuda acreditada por documentos con determinada virtualidad probatoria y que, en función de la conducta del deudor, puede abocar en el pago, en un proceso de ejecución o declarativo ordinario en función de la cuantía, dependiendo de si el deudor no se opone o se opone, respectivamente 4 .

De la lectura del art. 676 del CPC, podemos apreciar que queda excluida de esta clase de proceso cualquier otra pretensión distinta al pago de una suma de dinero, tales como obligaciones de dar, hacer o no hacer, lo cual resulta lógico en virtud de la ausencia de toda fase declarativa. Siguiendo lo dispuesto en dicho precepto, por vencida habrá de tenerse en cuenta si la efectividad del crédito se ha hecho depender por las partes del transcurso de un periodo de tiempo, y en su caso, si el deudor ha incurrido en mora en base a lo establecido en el artículo 1355 del Código Civil de Honduras 5 . Por exigible, cierta parte

4 GIMENO, V. (2016), Derecho Procesal Civil II. Los Procesos Especiales, Madrid, España, ediciones jurídicas Castillo Luna. 5 El obligado incurre en mora: 10.- Cuando no ha cumplido la obligación dentro del término estipulado, salvo que la ley, en casos especiales, exija que se requiera al deudor para constituirle en mora; 20.- Cuando la cosa no ha podido ser dada o ejecutada sino dentro de cierto espacio de tiempo, y el deudor lo ha dejado pasar sin darla o ejecutarla; 3o.- En los demás casos, cuando el 
de la doctrina ${ }^{6}$ considera que debe entenderse a la necesidad que el acreedor haya cumplido con sus obligaciones prestacionales para con el deudor, cumpliendo así con la totalidad de las condiciones precisas para que su derecho de crédito dinerario pueda ser reconocido por un tribunal como un crédito exigible.

La legislación hondureña a diferencia de la actual legislación española ${ }^{7}$, fija un límite en la cuantía para acceder al proceso monitorio, sin embargo, debemos resaltar que la versión original de la LEC, igualmente fijaba un límite máximo de cinco millones de pesetas (posteriormente cambiada a euros). Este límite fue finalmente suprimido por la ley $37 / 2011$, la cual introdujo diversas reformas como mecanismo de agilización procesal, y específicamente en el monitorio, debido a que se apreció un mayor volumen en el ingreso de demandas, lo cual consideraron como un indicativo de la confianza que existía por parte de la ciudadanía en la administración de justicia.

\section{COMPETENCIA Y JUSTIFICACIÓN DE LA DEUDA.}

En relación a la competencia, puede apreciarse que en el art. $678 \mathrm{CPC}$ se regula una competencia de carácter objetiva por razón de la cuantía, y territorial de carácter general. En relación a la competencia objetiva debemos tener en cuenta lo establecido en el artículo 29 del CPC antes citado que atribuye la competencia de los Juzgados de Letras y de Paz, en sintonía con el auto acordado dictado por la Corte Suprema de Justicia en punto deudor ha sido judicialmente reconvenido por el acreedor. 6 GARBERÍ, J. (2011), La Reclamación de Créditos impagados: vía procesal específica; editorial Bosch S.A.

7 Véase art. 812.1 de la Ley 1/2000, de 7 de enero. número 11 A del acta No. 10-2016 publicado en el diario oficial La Gaceta en fecha 13 de septiembre del 2016 No, 34,137. En el derecho comparado, puede apreciarse que en España los Jueces de Paz nunca podrán conocer de los procesos monitorios, ni siquiera en aquellos supuestos en que la cuantía de la demanda no supere los 90 euros $^{8}$, en virtud que el asunto se encuentra exclusivamente atribuido a los Juzgados de Primera Instancia de conformidad al artículo 813 LEC. En otros países la competencia para esta clase de proceso puede recaer en otra autoridad no jurisdiccional pero de carácter judicial, como es el Secretario do Tribunal (Portugal), Hussier de Justice (Francia), y Rechtspfleger (Alemania) ${ }^{9}$. Estos criterios de competencia en autoridades no jurisdiccionales, en su mayoría responden a la adopción de medidas para aliviar la carga jurisdiccional de los jueces, y que estos últimos solo intervengan cuando exista oposición de la parte demandada.

En lo que respecta a la justificación de la deuda, de la redacción del art. 677 del CPC puede apreciarse que para la justificación del derecho de crédito no se ha establecido un numerus clausus, sino apertus, y a nuestro criterio meramente ejemplificativo de sus diversas formas. Es importante tener en cuenta que, dada la naturaleza del proceso monitorio, esta justificación de la deuda no debe entenderse como plena prueba, ya que ello es aplicable a los procesos declarativos (ordinario y abreviado), sino que debe ser

\footnotetext{
$8 \quad$ El art. 47 de la Ley $1 /$ 2000, de 7 de enero, establece que: “A los Juzgados de Paz corresponde el conocimiento, en primera instancia, de los asuntos civiles de cuantía no superior a 90 euros que no estén comprendidos en ninguno de los casos a que, por razón de la materia, se refiere el apartado 1 del artículo 250".

9 GIMenO, V. (2016), Derecho Procesal Civil II. Los Procesos Especiales, Madrid, España, ediciones jurídicas Castillo Luna.
} 
entendida de manera que se genere al Juez un principio de prueba, equivalente al fumus boni iuris que rige en materia cautelar.

\section{ADMISION}

Para la admisión de la demanda monitoria, debe seguirse un criterio flexible y no limitado que impida el acceso o finalidad de este novedoso proceso en nuestro ordenamiento procesal, ya que el deudor posee el derecho de oposición que posteriormente abordaremos. Es basta la jurisprudencia española que ha establecido que "elemento esencial de este procedimiento consiste en que con la solicitud han de acompañarse documentos de los que resulte fundamento de buena apariencia jurídica de la deuda. En este aspecto se ha de serflexible en cuanto a la documentación que posibilite el acceso a este proceso ${ }^{10}$ ".

A diferencia de Honduras, en el modelo español el funcionario encargado de la admisión de lademanda monitoria es elLetrado de la Administración de Justicia (equivalente al Secretario Judicial). Ello responde al hecho que en España se estimó que algunos actos del procedimiento no pertenecían a la potestad jurisdiccional propiamente dicha, y que por tanto podían ser asumidas por otros funcionarios, aliviando así la carga del Juez.

Otro aspecto a resaltar del ordenamiento español, es el hecho que se establece en el art.815.4 LEC, la obligación de apreciar de oficio la concurrencia de cláusulas abusivas que constituyan el fundamento de la petición o que hubieren determinado la cantidad

10 Audiencia Provincial de Gran Canaria. Proceso 372/ 2017, auto de fecha 26 de junio; entre otras. exigible, siempre que la reclamación se funde en un contrato celebrado entre empresario o profesional y consumidor o usuario. Esta regulación fue introducida en España, a partir de la jurisprudencia establecida por el Tribunal de Justicia de la Unión Europea (TJUE), el cual ha declarado que "el juez nacional deberá apreciar de oficio el carácter abusivo de una cláusula contractual incluida en el ámbito de la Directiva 93/13 y, de este modo, subsanar el desequilibrio que existe entre el consumidor y el profesional, tan pronto como dispongan de los elementos de hecho y de derecho necesarios para ello ${ }^{11}$ ".

\section{POSIBLES CONDUCTAS DEL DEUDOR ANTE EL REQUERIMIENTO DE PAGO.}

En los casos que el deudor no atienda el requerimiento de pago, ni presente oposición, el Juez dictara auto por el cual mandara a iniciar la ejecución. Cierta parte de la doctrina considera que en estos casos el proceso monitorio no habría tenido éxito dado que el deudor no ha pagado $^{12}$, posición que no compartimos, al contrario, consideramos que este es el gran éxito del monitorio, que ante la falta de oposición del deudor, aquel simple documento aportado inicialmente, adquiera fuerza ejecutiva en un plazo sumamente rápido. Debemos señalar que, en la práctica jurídica hondureña, existe una tendencia a considerar que una vez dictado el auto antes referido, lo que continúa son actos ejecutivos dentro del mismo proceso monitorio, sin embargo, lo correcto es entender que con el 11 Tribunal de Justicia de la Unión Europea, sentencias de fecha 14 de marzo de 2013 y 26 de enero del 2017.

12 ROBLES, J. (Director-coordinador); FONTESTAD, L.; y otros. (2017). Conceptos de Derecho Procesal Civil; editorial Tecnos. 
auto mediante el cual se manda a iniciar la ejecución finaliza el proceso monitorio, y luego prosigue un proceso de ejecución de título judicial, el cual deberá iniciar con la solicitud de ejecución prevista en el art. 757 del CPC.

Otra posibilidad que asiste al demandado es ejercer su derecho de oposición, lo cual evidentemente produce la finalización del proceso monitorio, y que el asunto sea resuelto definitivamente a través del proceso ordinario u abreviado por razón de la cuantía de la reclamación ${ }^{13}$. De acuerdo al artículo 684.1 en relación al 32 del CPC, el Juez que conoció del proceso monitorio, mantendrá la competencia para el proceso declarativo correspondiente. Sobre este acto procesal existen dos posiciones, una que sostiene que nos encontramos ante una oposición genérica, y por tanto resulta suficiente la negativa al requerimiento de pago. En cambio, existe otra que sostiene la necesidad de indicar motivos de oposición en forma específica, y en caso que no se realice resulta admisible su subsanación. La postura mayoritaria coincide en que al menos de forma sucinta debe proporcionarse en el escrito de oposición los motivos por los cuales el deudor se opone al requerimiento, sin que ello implique esgrimir los argumentos jurídicos talladamente de los que pueda disponer ${ }^{14}$.

13 De conformidad al artículo 399.2, se conocerán por el ámbito del proceso ordinario las demandas cuya cuantía supere los cien mil lempiras (L.100, 000.00), y hasta dicha la cantidad por el ámbito del proceso abreviado conforme al artículo 400.2 ambos del CPC.

14 GOMEZ, J., BARONA, S., CALDERON, P. (Coordinadores) y otros. (2012), El Derecho Procesal Español del Siglo XX a Golpe de Tango, Valencia, España, editorial Tirant lo Blanch.

\section{EL PROCESO MONITORIO EN MATERIA DE PROPIEDAD HORIZONTAL.}

En España, la LEC establece en el artículo 812.2, la posibilidad de acudir al proceso monitorio para la reclamación de deudas que se acrediten mediante certificaciones de impago de cantidades debidas en concepto de gastos comunes de comunidades de propietarios de inmuebles urbanos, precepto que se encuentra relacionado con el artículo 21 de la Ley de Propiedad Horizontal de dicho país ${ }^{15}$.

Para su interposición se exige certificación previa de la junta aprobando la liquidación de la deuda con la comunidad de propietarios, con el visto bueno del presidente, siempre que tal acuerdo haya sido notificado a los propietarios afectados. A la cantidad reclamada, puede añadirse los gastos de requerimiento previo, siempre que conste documentalmente su realización, y se acompañe el justificante del gasto. Esta regulación no se encuentra prevista en el proceso monitorio hondureño, ya que esta clase de reclamación únicamente se prevé en la especialidad de propiedad horizontal (art. 620 al 622 CPC) que se tramita a través del proceso abreviado, sin embargo, resulta de interés para su incorporación a través de futuras reformas legislativas dado a sus resultados positivos.

Algunos autores consideran que con esta regulación se fortalece la efectividad del

$15 \mathrm{El}$ art. 21 de la Ley 49/ 1960, de 21 de julio establece que "las obligaciones a que se refieren los apartados e) y f) del artículo 9 deberán cumplirse por el propietario de la vivienda o local en el tiempo y forma determinados por la Junta. En caso contrario, el presidente o el administrador, si así lo acordase la junta de propietarios, podrá exigirlo judicialmente a través del proceso monitorio". 
crédito en un proceso como el monitorio. Tomando en consideración aspectos como la competencia territorial del lugar en donde radique la comunidad de vecinos, o sea, la del acreedor; se otorga a la comunidad de propietarios capacidad para ser parte; se establece un régimen de obligados solidarios de los diversos propietarios; exención de caución para la práctica de embargo preventivo, entre otros ${ }^{16}$.

\section{CONCLUSIONES}

PRIMERA: La introducción del proceso monitorio en el proceso civil hondureño fortalece la seguridad jurídica del país, al brindar un proceso judicial de reclamación rápida de créditos en mora, a diferencia de los procesos declarativos (ordinario y abreviado) que poseen una duración considerable en el tiempo.

SEGUNDA: La verdadera eficacia del proceso monitorio radica que, ante la falta de oposición del deudor requerido, aquel simple documento aportado inicialmente con la demanda, obtiene fuerza ejecutiva en los mismos términos que una sentencia firme de condena.

TERCERA: El proceso monitorio es un proceso judicial dirigido a tutelar de forma rápida y eficaz deudas dinerarias, vencidas y exigibles, de cantidad determinada, sin embargo, consideramos que pudiera obtenerse un mayor provecho de esta figura si se ampliara su ámbito de aplicación. En este 16 BONET, J. (2005), Proceso monitorio con especialidades en materia de propiedad horizontal: veinte cuestiones polémicas y una perspectiva general previa; Practica de Tribunales No. 17, sección Estudios, editorial La Ley. sentido, y tras nuestra investigación se realiza las propuestas de mejora siguientes:

1. La regulación actual del proceso monitorio admite como cuantía máxima de reclamación doscientos mil lempiras (L.200, 000.00), sin embargo, si en las estadísticas del Poder Judicial se llega apreciar un mayor volumen en el ingreso de esta clase de demandas, sería aconsejable suprimir dicho límite para evitar limitaciones de acceso a este procedimiento a una mayor cantidad de deudas.

2. Que se amplíe su ámbito de aplicación a pretensiones consistentes en impago de cantidades debidas en concepto de gastos comunes de comunidades de propietarios de inmuebles urbanos (propiedad horizontal), la cual en los últimos años ha tenido un mayor auge en Honduras, y que por ende generara mayores índices de litigiosidad en esa materia.

3. Que se establezca la obligación del Juez de revisar de oficio al momento de la admisión de la demanda, la existencia de posibles cláusulas abusivas cuando la demanda monitoria se base en un contrato celebrado entre empresario/profesional y consumidor/usuario, a efecto de subsanar el desequilibrio existente en la mayoría de los casos entre estos. 


\section{BIBLIOGRAFIA}

\section{A) DOCTRINA}

BONET, J. (2005), Proceso monitorio con especialidades en materia de propiedad horizontal: veinte cuestiones polémicas y una perspectiva general previa; Practica de Tribunales No. 17, sección Estudios, editorial La Ley.

GARBERÍ, J. (2011), La Reclamación de Créditos impagados: vía procesal específica; editorial Bosch S.A.

GIMENO, V. (2016), Derecho Procesal Civil II. Los Procesos Especiales, Madrid, España, ediciones jurídicas Castillo Luna.

GOMEZ, J., BARONA, S., CALDERON, P. (Coordinadores) y otros. (2012), El Derecho Procesal Español del Siglo XX a Golpe de Tango, Valencia, España, editorial Tirant lo Blanch.

Motiño, K. (2013) El Proceso Monitorio en el nuevo Código Procesal Civil Hondureño (Tesis Doctoral) Universidad Jaume I, www.uji.es.

ROBLES, J. (Director-coordinador); FONTESTAD, L.; y otros. (2017). Conceptos de Derecho Procesal Civil; editorial Tecnos.

\section{B) JURISPRUDENCIA}

Tribunal de Justicia de la Unión Europea, sentencia de fecha 14 de marzo de 2013.
Tribunal de Justicia de la Unión Europea, sentencia de fecha 26 de enero de 2017.

Audiencia Provincial de Gran Canaria, Proceso 372/ 2017, auto de fecha 26 de junio.

\section{C) LEGISLACION}

HONDURAS

Código Civil de 1906

Código Procesal Civil del 2006

\section{ESPAÑA}

Ley de Enjuiciamiento Civil 1/2000

Ley de Propiedad Horizontal 49/1960

Ley 37/2011 del 10 de Octubre 